\title{
A FAMILY OF WILKER'S INEQUALITIES IN TWO PARAMETERS AND ITS APPLICATIONS
}

\author{
XiaO-Diao Chen* ${ }^{*}$, Kang Yang, Sijie Gong And Ling Zhu
}

\begin{abstract}
Based on the reparameterization technique, this paper presents a family of Wilker's Inequalities with an extra parameter $\alpha$. By using Pade approximation, the optimal value of $\alpha$ within a local interval is given. And simple proofs are provided based on the bounds of the functions $\sin (\alpha x)$ and $\cos (\alpha x)$. With the constraint $\alpha=1$, the new method can recover several previous results. In principle, the idea can be extended to more other forms of bounding functions, or even more other inequality types. The comparison results show that the results in this paper are much better than those of prevailing methods.
\end{abstract}

Mathematics subject classification (2010): 26D15, 41A10, 42A16.

Keywords and phrases: Wilker's inequality, tighter bounds, reparameterization, trigonometric function, two-parameter function.

\section{REFERENCES}

[1] B. BAnjaC, M. MAKRAgić, B. MALEŠEvić, Some notes on a method for proving inequalities by computer, Results Math. 69 (1) (2016) 161-176.

[2] C. P. Chen, R. B. PARIS, Series representations of the remainders in the expansions for certain trigonometric functions and some related inequalities, Mathematical Inequalities \& Applications, 2017, 20 (4): 1003-1016.

[3] B. Zhang, C. P. Chen, Sharpness and generalization of Jordan, Becker-Stark and Papenfuss inequalities with an application, Journal Of Mathematical Inequalities, 2019, 13 (4): 1209-1234.

[4] X.-D. Chen, J. SHI, Y. WANG, X. PAN, A new method for sharpening the bounds of several special functions, Results Math. 72 (1-2) (2017) 695-702.

[5] X.-D. Chen, S. Jin, L. Chen, Y. WANG, A new method for refining the Shafer's equality and bounding the definite integrals, Results Math. 73 (2) (2018) 78.

[6] X.-D. ChEn, J. Y. MA, J. P. Jin, Y. G. WANG, A two-point-Padé-approximant-based method for bounding some trigonometric functions, J. Inequal. Appl. 2018, 140 (2018) 1-15.

[7] P. J. DAVIS, Interpolation and approximation, Dover Publications, New York, 1975.

[8] L. Debnath, C. Mortici, L. Zhu, Refinements of Jordan-Steckin and Becker-Stark inequalities, Results Math. 67 (1-2), 207-215 (2015).

[9] W. D. Jiang, Q. M. LuO, F. QI, Refinements and sharpening of some Huygens and Wilker type inequalities, Mathematical Inequalities \& Applications, 6 (1) (2014): 19-22.

[10] T. Lutovac, B. Malesevic, C. MorTici, The natural algorithmic approach of mixed trigonometric-polynomial problems, J. Inequal. Appl. 2017, 1 (2017), https://doi.org/10.1186/s13660-017-1392-1.

[11] T. Lutovac, B. Malešsević, C. Mortici, The natural algorithmic approach of mixed trigonometric-polynomial problems, Journal of Inequalities and Applications 116 (2017) 1-16.

[12] B. Malešević, T. Lutovac, M. RašAjSki, C. Mortici, Extensions of the natural approach to refinements and generalizations of some trigonometric inequalities, Advances in Difference Equations, 90 (2018): 1-15.

[13] B. MALEŠEVIĆ, T. LUTOVAC, M. RAŠAJSKI, et al., Extensions of the natural approach to refinements and generalizations of some trigonometric inequalities, J. Advances in Difference Equations, 2018, 2018 (1): 90. 
[14] B. MALEŠEVIĆ, M. MAKRAGIC, A method for proving some inequalities on mixed trigonometric polynomial functions, Journal of Mathematical Inequalities, 10 (2015): 849-876.

[15] B. MALEŠEvić, B. BANJAC, I. Jovović, A proof of two conjectures of Chao-Ping Chen for inverse trigonometricfunctions, Journal of Mathematical Inequalities 11 (1): 151-162 (2017).

[16] B. MalešEvić, T. Lutovac, B. BAnJAC, A proof of an open problem of Yusuke Nishizawa for a power-exponential function, Journal of Mathematical Inequalities, 12 (2): 473-485 (2018).

[17] B. Malesevic, T. Lutovac, B. BAnJAC, A proof of an open problem of Yusuke Nishizawa for a power-exponential function, J. Math. Inequal. 12 (2), 473-485 (2018), https://doi.org/10.7153/jmi-2018-12-35.

[18] C. MorticI, The natural approach of Wilker-Cusa-Huygens inequalities, Math. Inequal. Appl. 14 (2011) 535-541.

[19] C. MorTiCI, A subtly analysis of Wilker inequation, Appl. Math. Comput. 231 (2014) 516-520.

[20] B. MALesevic, M. MAKRAGIC, A method for proving some inequalities on mixed trigonometric polynomial functions, J. Math. Inequal. 10 (3), 849-876 (2016), https://doi.org/10.7153/jmi-11-63.

[21] B. MALESEVIC, B. BANJAC, One method for proving polynomial inequalities with real coefficients, Proceedings of 28-th TELFOR Conference, 2020. (978-0-7381-4243-2/20/)

[22] E. Neuman, Wilker and Huygens-type inequalities for the generalized trigonometric and for the generalized hyperbolic functions, Appl. Math. Comput., 230 (3) (2014) 211-217.

[23] M. Nenezić, L. ZHu, Some improvements of Jordan-Steckin and Becker-Stark inequalities, Applicable Analysis and Discrete Mathematics, 12 (2018), 244-256.

[24] M. Nenezić, B. Malesević, C. Mortici, New approximations of some expressions involving trigonometric functions, Appl. Math. Comput., 283 (2016) 299-315.

[25] J. S. Sumner, A. A. Jagers, M. Vowe, J. Anglesio, Inequalities involving trigonometric functions, Am. Math. Monthly 98 (3) (1991) 264-267.

[26] J. B. WiLKer, Problem E-3306, Am. Math. Monthly 96 (1989) 55.

[27] S. H. WU, H. M. SRIVASTAVA, A further refinement of Wilker's inequality, Integral Transforms \& Special Functions, 19 (10) (2008) 757-765.

[28] S. H. WU, H. P. YU, Y. P. DENG, et.al., Several improvements of Mitrinovic-Adamovic and Lazarevic's inequalities with applications to the sharpening of Wilker-type inequalities, Journal of nonlinear sciences and its applications 9 (4) (2016) 1755-1765.

[29] S. H. WU, S. G. LI, M. BEncze, Sharpened versions of Mitrinovic-Adamovic, Lazarevic and Wilker's inequalities for trigonometric and hyperbolic functions, Journal of nonlinear sciences and its applications 9 (5) (2016) 2688-2696.

[30] Z. H. YANG, Y. M. CHU, X. H. ZHANG, Sharp Cusa type inequalities with two parameters and their applications, Appl. Math. Comput., 268 (2015) 1177-1198.

[31] L. ZHU, A refinement of the Becker-Stark inequalities, Math. Notes 93 (3-4), 421-425 (2013).

[32] L. ZHU, New bounds for the exponential function with cotangent, Journal of Mathematical Inequalities (2018).

[33] L. ZHU, M. NENEZIĆ, New approximation inequalities for circular functions, Journal of Inequalities and Applications, 2018, 2018 (1).

[34] L. ZHU, Sharp inequalities of Mitrinovic-Adamovic type, Revista de la Real Academia de Ciencias Exactas, Físicas y Naturales. Serie A. Matemáticas, 113 (2), 957-968, 2019.

[35] L. ZHU, An unity of Mitrinovic-Adamovic and Cusa-Huygens inequalities and the analogue for hyperbolic functions, Revista de la Real Academia de Ciencias Exactas, Físicas y Naturales. Serie A. Matemáticas, 113 (4), 3399-3412, 2019.

[36] L. ZHU, On Frame's inequalities Journal of Inequalities and Applications, 94, 1-14, 2018. 